\title{
SUSTENTABILIDADE E CRISE AMBIENTAL: A NECESSIDADE DE UMA FUNÇÃO ECOLÓGICA DO ESTADO NA PÓS-MODERNIDADE
}

\author{
Marcos Leite Garcia ${ }^{1}$
}

Sérgio Ricardo Fernandes de Aquino ${ }^{2}$

Resumo: O objeto de estudo deste texto é a Função Ecológica do Estado como pressuposto ao acesso e desenvolvimento do Direito às Cidades Sustentáveis diante da crise ambiental mundial. Nesse caso, estabelece-se, como objetivo geral, demonstrar como a crise ambiental mundial, orientada pela Sustentabilidade, reivindica o cumprimento de seus objetivos no cenário nacional por meio da Função Ecológica do Estado. O método utilizado para a investigação é o Dedutivo. Ao final do artigo, verifica-se que a Função Socioambiental não atende as exigências da Sustentabilidade em prol do Direito às Cidades Sustentáveis.

Palavras-Chave: Crise Ambiental. Função Ecológica do Estado. Função Socioambiental. PósModernidade. Sustentabilidade.

\section{SUSTAINABILITY AND ENVIROMENTAL CRISIS: THE NEED FOR AN ECOLOGICAL FUNCTION OF THE STATE IN POST-MODERN AGE}

\begin{abstract}
The object of study of this text is the Ecological Function of the State as an assumption to access and development of the Right to Sustainable Cities in the global environmental crisis. It is established, as a main objective, to demonstrate how the global environmental crisis, guided by Sustainability, claims the fulfillment of its objectives in the national scenario through the Ecological Function of the State. The method used for the investigation is the Deductive. At the end of the article, it appears that the Environmental and Social function does not meet the requirements of Sustainability in favor of the Right to Sustainable Cities.
\end{abstract}

Key-Words: Ecological Function of the State. Enviromental crisis. Enviromental and Social Function of the State. Post-Modern Age. Sustainability.

\section{INTRODUÇÃO}

\footnotetext{
${ }^{1}$ Doutor em Direito pela Universidade Complutense de Madrid (2000). Realizou pós-doutorado na Universidade Federal de Santa Catarina (2012). Professor do Programa de Pós-graduação stricto sensu em Ciência Jurídica mestrado e doutorado - da Universidade do Vale do Itajaí (UNIVALI) e professor do Curso de Mestrado em Direito da Universidade de Passo Fundo (UPF). Autor de diversos artigos sobre Direitos Fundamentais. E.mail: mleitegarcia@terra.com.br

${ }^{2}$ Doutor em Ciência Jurídica pela Universidade do Vale do Itajaí. Professor Permanente e Pesquisador do Programa de Mestrado em Direito da Faculdade Meridional - IMED. Currículo Lattes: http://lattes.cnpq.br/1318707397090296 - E-mail: sergiorfaquino@gmail.com
} 
A efetividade da Sustentabilidade ${ }^{3}$ tem sido um dos desafios mais significativos do século XXI. A crise ambiental mundial e seus efeitos difusos aumentam a complexidade das respostas e atitudes para que haja uma mitigação em torno das catástrofes que ocorrem em todos os territórios do mundo. Sob igual argumento, na medida em que se observa a intensificação dessa crise, em sentido oposto, as forcas políticas nacionais não querem criar alternativas de cooperação em torno da governança dos Bens Comuns Globais.

Encontrar a sincronia e interesses entre o local e o global pode ser descrita como a peça fundamental deste enorme quebra-cabeça. A Sustentabilidade encontra o seu vigor, a sua efetividade a partir dessa combinação. No entanto, se nos detivermos à análise do Direito às Cidades Sustentáveis, pouco se tem realizado como meta de governança da Sustentabilidade. É chegado o momento de rever o significado da Função Social do Estado como orientação de viabilidade para o desenvolvimento de políticas urbanas no Brasil.

O Objetivo Geral deste estudo é demonstrar como a crise ambiental mundial, orientada pela Sustentabilidade, reivindica o cumprimento de seus objetivos no cenário nacional por meio da Função Ecológica do Estado. Os Objetivos Específicos podem ser traduzidos pelas seguintes ações: a) evidenciar os efeitos da crise ambiental mundial; b) avaliar, diante da crise ambiental mundial, se a Função Socioambiental atende às exigências da Sustentabilidade para favorecer o acesso e o desenvolvimento do Direito às Cidades Sustentáveis.

O problema de pesquisa ao tema estudado sugere a seguinte indagação: É possível que a partir da adoção da Sustentabilidade como paradigma de conservação da vida, a Função Socioambiental do Estado - entendida como princípio de política urbana - se torne um projeto viável de efetividade contra os efeitos da crise ambiental mundial?

A hipótese de pesquisa sugere, provisoriamente, que os danos ambientais ocorridos devido à falta de cooperação e articulação de bens comuns globais enfraquecem a efetividade de legislações ambientais nacionais, especialmente quanto à necessidade de politicas urbanas compatíveis com a exigência da Sustentabilidade. A proteção constitucional sobre o Direito à

3 Os autores utilizarão o seguinte Conceito Operacional para a Categoria mencionada: É a compreensão ecosófica acerca da capacidade de resiliência entre os seres e o ambiente para se determinar - de modo sincrônico e/ou diacrônico - quais são as atitudes que favorecem a sobrevivência, a prosperidade, a adaptação e a manutenção da vida equilibrada. 
Cidade Sustentável se torna simples ideologia na medida em que não há correspondência entre os âmbitos jurídicos local e global de mitigação à crise ambiental.

Por esse motivo, é necessário que haja sincronia entre os diferentes espaços de produção, interpretação e aplicação de um Direito que não se satisfaz tão somente na perspectiva universal e local. O desenvolvimento de uma politica urbana na qual contemple a importância da Natureza como fator estratégico vital à ecologia da cidade somente se manifesta quando essas forças complementares legais consolidarem - tanto no sentido sincrônico quanto diacrônico - os objetivos determinados pelo imperativo ético da Sustentabilidade, por um lado, e a implementação de seu entendimento científico por outro.

O método utilizado para a Fase de Investigação e o Relato de Pesquisa será o Dedutivo $^{4}$, cuja premissa maior são as reivindicações da Sustentabilidade diante da crise ambiental mundial e, como premissa menor, se a Função Ecológica do Estado atende às demandas sustentáveis no cenário nacional. Para se desenvolver a Fase de Tratamento dos Dados, selecionou-se o Método Cartesiano ${ }^{5}$. As técnicas selecionadas ao cumprimento dos métodos eleitos são a Pesquisa Bibliográfica e Documental ${ }^{6}$, a Categoria ${ }^{7}$ e o Conceito Operacional $^{8}$, quando necessários.

\section{SUSTENTABILIDADE E CRISE AMBIENTAL: INTERDEPENDENCIA GLOBAL E LIMITES SOBERANOS}

A crise ambiental, especialmente a partir da Segunda Guerra Mundial, evidenciou uma nova proporção de danos contra a humanidade e a biodiversidade planetária. A busca pelo progresso e crescimento econômico a qualquer preço expuseram as fragilidades de uma ideologia - cientifica, tecnológica e econômica - a qual insistia dividir o mundo em "países desenvolvidos" e "subdesenvolvidos". O domínio sobre a cooperação, a eliminação sobre a integração eram - e ainda são - cenários que apenas enaltecia a profundidade do abismo civilizacional vivido em torno da busca para a solução comum posta pela crise ambiental mundial.

\footnotetext{
4 “[...] base lógica da dinâmica da Pesquisa Científica que consiste em estabelecer uma formulação geral e, em seguida, buscar as partes do fenômeno de modo a sustentar a formulação geral". (PASOLD, 2018, p. 215).

5 “[...] base lógico-comportamental proposta por Descartes, [...], e que pode ser sintetizada em quatro regras: 1. duvidar; 2. decompor; 3. ordenar; 4. classificar e revisar". (PASOLD, 2018, p. 214).

6 “[...] Técnica de investigação em livros, repertórios jurisprudenciais e coletâneas legais". (PASOLD, 2018, p. 217).

7 “"[...] palavra ou expressão estratégica à elaboração e/ou à expressão de uma ideia”. (PASOLD, 2018, p. 207).

8 "[...] definição estabelecida ou proposta para uma palavra ou expressão, com o propósito de que tal definição seja aceita para os efeitos da ideia exposta". (PASOLD, 2018, p. 207).
} 
A excessiva interferência antropogênica nos processos, funções, estruturas e ciclos naturais entre os seres e seus ambientes intensificou a globalização dos riscos ${ }^{9}$ vividos pela humanidade. A falta de articulação política e jurídica entre as nações e organismos supranacionais - como se observou no início dos debates que ocorreram para a proposição da Declaração de Estocolmo - revelou a ausência de preocupação sobre aquilo que comumente pertence a todos e se torna necessário sinalizar os meios de acesso e utilização desses bens ou recursos comuns globais.

Nesse caso, duas tarefas precisam ocorrer para se entender esses cenários. Primeiro, a definição de termos como Bens ou Recursos Comuns, Bens Internacionais e Bens Globais. Em seguida, ilustra-se a preocupação com os Bens Comuns a partir da metáfora de Garret Hardin intitulada "A tragédia dos comuns".

Para Buck (1998, p. 5) os recursos oriundos de um espaço comum podem ser identificados no seguinte conceito operacional: “Common pool resources are subtractable resources managed under a property regime in which a legally defined user pool cannot be efficiently excluded from the resource domain”. Em outras palavras, os Bens Comuns, os quais pertencem a todos, podem ser extraídos sob um regime de propriedade no qual o usuário não poderá ser excluído desse domínio.

A Natureza, os seus ecossistemas e a biodiversidade, se tornam um exemplo dessa definição. Não obstante seja possível observar que os ambientes naturais estejam restritos às regras do Estado-nação, como é o caso da Amazônia, por exemplo, toda a teia da vida ali presente não pertence somente aos seus países, mas podem ser compartilhados com outros lugares e culturas a fim de promover a mitigação dos efeitos da crise ambiental.

Por outro lado, os Bens Comuns Internacionais, conforme Buck (1998, p. 6), são aqueles compartilhados por várias nações, como é o caso do Mar Mediterrâneo ou a Antártica. Os Bens Comuns Globais ${ }^{10}$, sob outro enfoque, podem ser entendidos pelos domínios dos quais

\footnotetext{
9 "Riscos não se esgotam, contudo, em efeitos e danos já ocorridos. Neles, exprime-se sobretudo um componente futuro. Este baseia-se em parte na extensão futura dos danos atualmente previsíveis e em parte numa perda geral de confiança ou num suposto 'amplificador do risco'. Riscos têm, portanto, fundamentalmente que ver com a antecipação, com destruições que ainda não ocorreram, mas que são iminentes, e que, justamente nesse sentido, já são reais hoje". (BECK, 2010, p. 39).

${ }^{10}$ Para Matias (2014, p. 17), os Bens Comuns Globais possuem algumas características: "Primeiro, e muito difícil, ou quase impossível, impedir que alguém usufrua deles. Uma das características dos bens comuns é que excluir alguém de utilizá-los tem um alto custo, pois isso tem que ser feitos por meios físicos - cercas - por exemplo ou institucionais - leis, policiamento, etc. Segundo, os bens comuns se degradam com o uso. Em outras palavras, a utilização desses recursos por alguém reduz a sua disponibilidade para os demais".
} 
todas as nações devem ter acesso. Cita-se como exemplo dessa afirmação o Espaço Sideral. A crise ambiental mundial revela a ausência dessa preocupação com os domínios comuns e seus recursos e como utilizá-los pela via da cooperação transversal. Essa atitude não apenas enfrenta a complexidade do tema que se acentua no decorrer do tempo, bem como favorece a superação de outras situações - pobreza, desnutrição, desigualdades sociais - em nações que não atingiram condições razoáveis para que todos tenham qualidade e dignidade de vida.

Nesse caso, Garret Hardin, em 1968, sinalizou esse cenário do esgotamento dos Bens Comuns por meio de um artigo sobre a "Tragédia dos Comuns". Este texto apresenta uma aldeia de pastores, os quais todos usavam um pasto comum para as suas ovelhas. Cada pastor, visando uma renda maior, colocava mais e mais ovelhas. Resultado: com o tempo não havia mais grama que servisse de alimento para as ovelhas e, logo, essas começaram a morrer de fome (MATIAS, 2014, p. 17). A situação descrita revela que: a) quando não se sabe gerenciar e cuidar dos Bens Comuns, especialmente porque numa relação de interdependência nenhum usuário pode ser excluído quanto ao seu acesso e utilização, o privado tende a suprir o espaço comum, como se constata com Hobbes ${ }^{11}$ e Locke ${ }^{12}$; b) esse "território de ninguém" sugere, também, uma terra de "não direito" (MATTEI, 2013, p. 25).

Quando não se observa um critério de governança sobre Bens Comuns Globais, a solução para a crise ambiental mundial se torna monetarizada. É necessário que hajam esforços para uma solidariedade sincrônica e diacrônica acerca do uso e acesso desses bens na medida em que o Homem toma consciência de seu lugar na cadeia vital. Essa "epifania", esse reconhecimento favorece o empreendimento de outras atitudes mais fortes capazes de alterar a realidade.

A crise ambiental destacou, portanto, a necessidade inicial de um valor moral no qual mitigasse os efeitos negativos dessas atitudes cujo o objetivo primário é a obtenção do lucro às custas dos seres humanos e não humanos. A Sustentabilidade, entendida, inicialmente, pelo seu triple bottom line $e^{13}$, e ampliada para sua matriz ecológica se torna algo mais enfático, como

\footnotetext{
${ }^{11}$ Vive-se para a comunidade ou para si? Hobbes (2007, p. 153) responde a indagação: “[...] se o interesse público vier a se misturar com o privado, prefere o privado porque as paixões dos homens são, por comum, mais fortes que a sua razão". Tradução livre do autor deste texto.

12 “[...] A superfície da terra que um homem trabalha, planta, melhora, cultiva e da qual pode utilizar os produtos, pode ser considerada a sua propriedade. Por meio de seu trabalho, ele a limita e separa do bem comum. Não bastará, para provar a nulidade de seu direito, dizer que todos os outros podem valer de um título igual, e que, em consequência disso, ele não pode se apropriar de nada, nada cercar, sem o consentimento conjunto de seus co-proprietários, ou seja, de toda a humanidade". (LOCKE, 2006, p. 100/101)

13 “[...] sustainable capitalism will need more than just environmental-friendly technologies and markets which actively promote dematerialization. It also needs to address radically new views of what is meant by social
} 
um imperativo ético do final do século XX em direção ao XXI. No entanto, a Sustentabilidade pareceu algo muito abstrato e cujos esforços parecem ser demasiadamente pesados para que haja uma cooperação global acerca dos Bens Comuns.

As várias cúpulas que ocorreram desde 1992, no Rio de Janeiro, até 2015 na França enfatizam um claro interesses nacional frente o global. A Sustentabilidade se tornou, nesse caso, um objetivo secundário. As evidências percebidas pela crise ambiental mundial, todavia, se mostram cada vez mais complexa e não pode ter respostas mais "simplistas"14. É necessário que haja uma Racionalidade da Sustentabilidade contra aquilo que Leff (2015, p. 23) chamou de "Ideologia do Desenvolvimento Sustentável:

[...] a ideologia do desenvolvimento sustentável desencadeia um delírio e uma inercia incontrolável de crescimento [...]. O discurso da sustentabilidade monta um simulacro que, ao negar os limites do crescimento, acelera a corrida desenfreada do processo econômico para a morte entrópica. A racionalidade econômica desconhece toda a lei de conservação e reprodução social para dar curso a uma degradação do sistema que transcende toda norma, referência e sentido para controla-lo. Se as ecosofias, a ecologia social e o ecodesenvolvimento tentaram dar novas bases morais e produtivas a um desenvolvimento alternativo, o discurso do neoliberalismo ambiental opera como uma estratégia fatal que gera uma inércia cega, uma precipitação para a catástrofe.

Esse delírio do Desenvolvimento travestido ou qualificado pela Sustentabilidade se torna uma mentira existencial, ou melhor, a de que a civilização ocidental adotou um paradigma de vida no qual não quer cumprir seus objetivos propostos. O desprezo, má-fé ou a ignorância sobre os limites de um planeta finito conduziram aos desastres observados em larga escala pela crise ambiental mundial.

Por esse motivo, as catástrofes ecológicas, a organização de movimentos sociais em prol da defesa ambiental, o surgimento de novas perspectivas jurídicas na América Latina, como os Direitos da Natureza, o empenho das Nações Unidas em articular estratégias para mitigas os efeitos do desastre ecossistêmico de origens antropogênicas

equity, environmental justice and business ethics. This will require a much better understanding not only of financial forms of capita, but also of natural, human and social capital”. (ELKINGTON, 1997, p. 72)

${ }^{14}$ Sob uma perspectiva da Teoria dos Sistemas, Bertanlanffy $(2008$, p. 83) acrescenta: "O significado da expressão um tanto mística 'o todo é mais que a soma das partes' consiste simplesmente em que as características constitutivas não são explicáveis a partir das características das partes isoladas. As características do complexo, portanto, comparadas às dos elementos, parecem 'novas' ou 'emergentes'. Se porem conhecermos o total das partes contidas em um sistema e as relações ente elas o comportamento do sistema pode ser derivado do comportamento das partes. Podemos também dizer: enquanto podemos conceber uma soma como sendo composta gradualmente, um sistema, enquanto total de partes com suas inter-relações, tem de ser concebido como constituído instantaneamente". 
Veja-se um outro caso similar sobre a intensidade dessa crise e seus efeitos contra a Sustentabilidade dos Bens Comuns Globais. Os argumentos utilizados para se demonstrar algumas características sobre o modus vivendi entre os seres e os ecossistemas e a necessidade de seu equilibrio mostra não apenas que as catástrofes naturais podem erradicar o ser humano, como, também, aquela autopromovida por meio da crise ambiental mundial. Tem-se, nesse momento, o surgimento de um "imaginário catastrófico", os quais podem ser sintetizados em três breves discursos: a) finitude do planeta; b) a autodestruição; c) incerteza no lugar da certeza científica.

O primeiro argumento significa que as evidencias científicas, a própria exploração do espaço revelaram a fragilidade e finitude de nosso planeta. Na verdade, precisa-se esclarecer alguns pontos sobre essa afirmação: 1) o que torna a Terra frágil é a manutenção dos processos, estruturas, funções e ciclos ao desenvolvimento das vidas. O necessário equilíbrio junto às condições para que haja uma interação sadia entre seres e ambientes. Tanto a disciplina Ecologia quanto a Ciência Ambiental ${ }^{15}$ fornecem os elementos primários para se entender a importância da Sustentabilidade ambiental e como esses preceitos estão ligados à dimensão social e econômica (Novamente: triple bottom line); 2) Ao se compreender a estrutura geofísica da Terra, contudo, essa fragilidade não parece tão significativa, afinal, nosso Planeta é capaz de suportar imensas quantidades de poluentes, de explosões - atômicas, vulcânicas, entre outros e permanecer quase com essa estrutura praticamente inalterada.

Junto a esses esclarecimento, o segundo argumento (b) - capacidade de autodestruição - surge por fatores históricos que demonstram como os seres humanos podem erradicar sua espécie da Terra. O perigo nuclear vivenciado pela época da Guerra Fria, a pobreza que assola diferentes países, entre outros. Dois fenômenos, contudo, chamam a nossa atenção: 1) o aumento da população na Terra; 2) a destruição da camada de ozônio e a ocorrência das mudanças climáticas.

Quanto ao primeiro tópico, observa-se, a partir do debate ambiental iniciado em Estocolmo, uma preocupação com a grande quantidade de pessoas a habitar a Terra, bem como

\footnotetext{
15 "Environmental science is a study of connections nature. It is an interdisciplinary study of (1) how the earth (nature) works and has survived and thrived, (2) how humans interact with the environment, and (3) how we can live more sustainably. It strives to answer several questions: What environmental problems do we face? How serious are they? How do they interact? What are their causes? How has nature solved such problems? How can we solve such problems? To answer such questions, environmental science integrates information and ideas from fields such as biology, chemistry, geology, geography, economics, political science, and ethics". (MILLER; SPOOLMAN, 2018, p. 5)
} 
a escassez que alimentos a qual seria a consequência dessa superpopulação. Cria-se, nesse sentido, um imaginário catastrófico o qual poderia sugerir a eliminação de determinadas nações para amenizar esse problema social, econômico e ambiental, conforme a critica neomalthusiana ${ }^{16}$. Sob o argumento da explosão demográfica ser uma preocupação da Sustentabilidade, Miller e Spoolman (2018, p. 16) advertem:

No one knows how many people the earth can support indefinitely. However, our large and expanding ecological footprints and the resulting widespread natural capital degradation are disturbing warning signs. Some analysts call for us to reduce environmental degradation by slowing population growth and level it off at around 8 billion by 2050 instead of 9.8 billion.

A autodestruição da Terra pode ser provocada pela vontade humana em permanecer com seu status de alta consumidora ou, ainda, quando iniciou, na década de 70 , as investigações científicas com interesses monetários. A partir dessa convergências, iniciou-se outro significativo debates, cujos efeitos globais são evidentes, bem como a ausência de uma preocupação política em termos e governança sobre a mudança climática. Hobsbawn (1995, p. 531) descreve como o fato ocorreu:

\begin{abstract}
Assim, em 1973, dois químicos, Rowland e Molina, notaram pela primeira vez que os fluorocarbonos (largamente usados em refrigeração e nos recém-populares aerossóis) consumiam o ozônio na atmosfera da Terra. Dificilmente isso poderia ter sido notado muito mais cedo, pois a liberação desses produtos químicos (CFC 11 e CFC 12) não totalizava 40 mil toneladas antes do início da década de 1950. (Mas entre 1960 e 1972 mais de 3,6 milhões de toneladas deles haviam entrado na atmosfera.). Contudo, no início da década de 1990 a existência de grandes 'buracos de ozônio' na atmosfera era do conhecimento de leigos, e a única questão era saber com que rapidez ia prosseguir o esgotamento da camada de ozônio, e quando ultrapassaria os poderes de recuperação natural da Terra. Se se eliminassem os CFCs, ninguém tinha dúvidas de que ela reapareceria. $\mathrm{O}$ 'efeito estufa', ou seja, o incontrolável esquentamento da temperatura global pela liberação de gases produzidos pelo homem, que começou a ser discutido a sério por volta de 1970, tornou-se uma preocupação importante de especialistas e políticos na década de 1980 [...].
\end{abstract}

Esse caso relatado por Hobsbawn implica em outras consequências deste imaginário catastrófico: a troca da certeza científica pela incerteza (argumento “c"). O medo causado pela fragilidade da Terra em manter condições ao desenvolvimento das vidas, somada à capacidade humana de se autodestruir permitiu que se manifestasse a seguinte reflexão: Os processos de industrialização, o domínio do Homem sobre a Natureza, bem como a amplitude do

\footnotetext{
16 "[...] la opinión de los paises en vías de desarrollo quedó reflejada en las palabras del representante del Brasil, Joao Augusto de Araujo Castro, quien criticó las posturas de los países ricos e industrializados de neomalthusianas, ya que identificaban como el gran problema ambiental del mundo, y por lo tanto el más urgente y prioritario de abordar, la llamada explosión demográfica. Por el contrario, de Araujo, señaló que el problema ambiental principal era la creciente contaminación provocada por los países industrializados, asi como los crecientes gastos en armamentos en que estos incurrían". (SAAVEDRA, 2018, p. 5)
} 
conhecimento cientifico trouxe não apenas benefícios e bem-estar às pessoas - especialmente aos "países desenvolvidos", mas, também, efeitos graves dessas pretensas conquistas humanas, tais como a redução ou desaparecimento dos Bens Comuns Globais, a contaminação industrial, a intensificação da pobreza e desigualdades sociais, entre outras consequências (SAAVEDRA, 2009, p. 80).

A crise ambiental mundial, a partir de sua complexidade e amplitude dos danos, revela algo antes não pensado: 1) os limites propostos pela Sustentabilidade quanto à condução das pesquisas científicas (HOBSBAWN, 1995, p. 532); 2) a crença ingênua de que a Ciência e a Tecnologia poderão recuperar ou "salvar" aquilo que já foi destruído (SAAVEDRA, 2009, p. 82). É necessário, por meio desse cenário, enfatizar a importância de uma governança para a Sustentabilidade, especialmente no que se refere à função do Estado em assegurar, como política urbana, o Direito à Cidade Sustentável.

\section{FUNÇÃO ECOLÓGICA DO ESTADO E O DIREITO ÀS CIDADES SUSTENTÁVEIS}

A necessidade de uma governança em prol da Sustentabilidade, no seu sentido ecológico, não ocorre apenas com os meios e as finalidades asseguradas constitucionalmente por meio do Estado-nação. Os efeitos difusos da crise ambiental e a ocorrência de cúpulas para se debater a necessidade de uma solidariedade sincrônica e diacrônica

Hayward ${ }^{17}$, a partir desse argumento, destaca a complementariedade, por exemplo, de forças jurídicas nacionais capazes de modificar a legislação internacional, bem como do espaço jurídico transnacional servir como om lócus privilegiado para se debater, articular e decidir assuntos que se referem ao bem comum de todos os seres.

A proteção dos Bens Comuns Globais, junto a outros modelos de governança, tais como a Transgovernança ${ }^{18}$, requer um modelo jurídico de cooperação Global. Por esse motivo

\footnotetext{
17 "[...] it is reasonable to suppose that the more that humans come to understand about the interconnectedness of their health and well-being with that nonhuman nature, the more inseparable appear their interests with the 'good' of nature”. (HAYWARD, 2005, p. 34).

18 "How does sustainability governance look when we recognise the concepts of knowledge democracy and second modernity? The best answer might be that we do not need a new paradigm, a new orthodoxy, but should develop the sensitivity to look beyond governance conventions. This implies an approach beyond traditional forms of governance, beyond disciplinary scientific research, towards more transdisciplinarity; beyond borders formed by states and other institutions, towards trans-border approaches; beyond conventional means to measuring progress, towards new and more interactive measuring methods; beyond linear forms of innovation, towards open innovation; beyond cultural integration or assimilation, towards looking for compatibility. In other words, governance for sustainable transformations requires thinking beyond standardised governance recipes, towards a culturally sensitive metagovernance for sustainable development. The combination of these steps beyond familiar sustainability governance, we call transgovernance. Transgovernance is an approach rather than a recipe. Using this approach, solutions may differ". (VELD, 2011, p. 288)
} 
que, acertadamente, Staffen (2018, p. XIII) tem insistido que esses bens não apenas precisam estar sob um domínio jurídico global (global legal domain), mas, ainda, estar sob o regime de um global rule of law.

Nessa linha de pensamento, surge uma indagação: a chamada função socioambiental da propriedade, para fins de política urbana, se torna um critério atento às demandas para uma Transgovernança em prol do Direito às Cidades Sustentáveis? Primeiro, a nossa Constituição Federal de 1988, em seu artigo $182, \S 2^{\circ}$ explicita, para fins de política urbana, a função social da propriedade urbana. A lei n. 10257/2001 - Estatuto da Cidade - amplia essa condição ao prescrever no Parágrafo Único do artigo $1^{\circ}$ e inciso I do artigo $2^{\circ}$, respectivamente, as seguintes condições:

[...] Para todos os efeitos, esta Lei, denominada Estatuto da Cidade, estabelece normas de ordem pública e interesse social que regulam o uso da propriedade urbana em prol do bem coletivo, da segurança e do bem-estar dos cidadãos, bem como do equilíbrio ambiental. Art. 2o A política urbana tem por objetivo ordenar o pleno desenvolvimento das funções sociais da cidade e da propriedade urbana, mediante as seguintes diretrizes gerais: I - garantia do direito a cidades sustentáveis, entendido como o direito à terra urbana, à moradia, ao saneamento ambiental, à infra-estrutura urbana, ao transporte e aos serviços públicos, ao trabalho e ao lazer, para as presentes e futuras gerações; [...]. (grifos nossos)

Soma-se à Função Social do Estado um complemento: o ambiental. Nesse caso, temse a Função Socioambiental do Estado. Todavia, essa última função citada demonstra o fenecimento da Soberania ${ }^{19}$ diante das exigências de Sustentabilidade à criação e manutenção de políticas públicas a fim de se assegurar o Direito às Cidades Sustentáveis. A crise ambiental mundial já evidenciou, muitas vezes, como o critério ambiental padece diante dos interesses sociais e econômicos.

A Função Socioambiental, portanto, sinaliza uma incongruência com a Sustentabilidade - ou, em outras palavras, parece algo criado por mentalidades ideológicas hipócritas (MANNHEIM, 1982, p. 219) -, pois: 1) as duas - Função Social e Ambiental sempre são aplicadas ao mesmo tempo; 2) os interesses de ambas são distintos e, geralmente, o ambiente será sacrificado em prol da manutenção e progresso econômico. Por esse motivo, Araújo (2018, p. 265/266):

\footnotetext{
19 “O pretenso Poder Soberano do Estado Constitucional Moderno, pode-se dizer, encontra-se em adiantado processo de deterioração. Não é o Poder que desaparece, mas sim uma forma específica de sua organização e que teve seu ponto forte no conceito jurídico-político de Soberania”. (CRUZ, 2011, p. 88)
} 
[...] a obrigação de defesa do meio ambiente e a função social da propriedade condicionam a forma de valoração dos bens para a finalidade de apropriação. Em decorrência disso, qualquer relação de apropriação deve permitir o cumprimento de duas funções distintas: uma individual (dimensão econômica da propriedade), e uma coletiva (dimensão socioambiental da propriedade). [...] É possível, portanto, afirmar que função ambiental e função social são distintas. Esta diz respeito ao uso da propriedade no interesse social. Aquela, ao uso da propriedade no interesse ambiental.

A leitura dessa afirmação indica que se ambas funções são distintas, não há como assegurar o cumprimento da Função Socioambiental a partir do significado ecológico da Sustentabilidade. Na verdade, como ressalta a autora (2018, p. 270): “[...] nem sempre o exercício da função social ou o 'uso racional' da propriedade é melhor para o meio ambiente. Há situações em que 'não usá-la' pode melhor atender ao interesse ambiental".

O termo utilizado por Araújo, contudo, parece também não satisfazer as demandas de uma integração jurídica local e global. Para fins de cumprimento aos objetivos da Sustentabilidade - entendidos como pressuposto ao Direito às Cidades Sustentáveis - torna-se necessária uma Função Ecológica do Estado.

A Sustentabilidade, na sua dimensão ecológica, deve ser interpretada como vetor de Poder que limita e condiciona o agir nacional frente à utopia do Bem Comum Global. A tarefa dessa compreensão surge na Sensibilidade Jurídica ${ }^{20}$ e na Consciência Jurídica ${ }^{21}$ de um Povo ${ }^{22}$ ou da Humanidade ${ }^{23}$. Essas são as linhas que tecem a alvorada desse tempo de transição denominada - para fins didáticos - de Pós-Modernidade.

Por esse motivo, deve-se preparar condições de outra vida mais digna e que corresponde às demandas do tempo presente, do século XXI, requer a identificação desses

\footnotetext{
${ }^{20}$ Utiliza-se o seguinte conceito operacional para essa categoria: é o ato de sentir algo junto à pluralidade de seres, lugares, momentos e linguagens que constituem a vitalidade e dinâmica da Terra, cujas diferentes maneiras de cumplicidade denotam condições de pertença e participação, as quais precisam ser expressas pelo Direito [continental ou global] para assegurar as manifestações - históricas ou normativas - sobre a importância do desvelo da Alteridade no vínculo comunicacional entre humanos e não-humanos.

21 "Aspecto da Consciência Coletiva [...] que se apresenta como produto cultural de um amplo processo de experiências sociais e de influência de discursos éticos, religiosos, etc., assimilados e compartilhados. Manifestase através de Representações Jurídicas e de Juízos de Valor”. (MELO, 2000, p. 22). Grifos originais da obra em estudo.

22 “[...] o povo não é apenas - de forma indireta - a fonte ativa da instituição de normas por meio de eleições bem como - de forma direta - por meio de referendos legislativos; ele é de qualquer modo o destinatário das prescrições, em conexão com deveres, direitos e funções de proteção. E ele justifica esse ordenamento jurídico num sentido mais amplo como ordenamento democrático, à medida que o aceita globalmente, não se revoltando contra o mesmo". (MÜLLER, 2009, p. 49).

23 “[...] A responsabilidade para com a humanidade também pressupõe um vínculo, mas um vínculo cosmopolita, desta vez, portanto, universal. Trata-se, certamente, de uma responsabilidade comum, que é imposta aos indivíduos e às coletividades, devido ao vínculo pré-originário porque nos faz quem somos. Esse vínculo préoriginário é a pertença à Terra antes de qualquer percepção, de qualquer pensamento e da ação. Ora, essa pertença significa que não é a Terra que nos pertence, mas que nós pertencemos a ela: trata-se de algo que se encontra em um nível acima de qualquer apropriação, em suma, é inapropriável”. (ZARKA, 2014, p. 46).
} 
valores que não se fixam em determinado momento histórico, mas, na verdade, a sua "atemporalidade" significa que o seu conteúdo está vivo dentro das novas exigências do convívio presenteísta.

O Direito e o Estado da Pós-Modernidade se caracterizam, segundo Gervasoni (2017, p. 170, grifos originais da obra em estudo), pelo “[...] pragmatismo e relativismo, pela aceitação do descentramento do sujeito, por uma pluralidade das racionalidades, pelo risco, pelo retorno da sociedade civil e pela apreensão das relações jurídicas na complexidade das lógicas bruscamente estilhaçadas".

O Estado e o Direito, ao esboçarem a aplicação de uma Função Ecológica, fomentam o compromisso global da Sustentabilidade e de seus critérios para que hajam alternativas ao desenvolvimento de uma Transgovernança entre o local e o global. Eis uma das "novidades do novo" que aparecem como desafios a ambas entidades na transição histórica da Modernidade para outro momento ainda inominado o qual intitula-se Pós-Modernidade ${ }^{24}$.

Não obstante a Sustentabilidade seja o compromisso global para uma vida digna, no seu sentido mais amplo, a Função Ecológica do Estado e do Direito na Pós-Modernidade surge com caráter de princípio constitucional a fim de rememorar cidadãos e agentes estatais novamente no seu sentido mais amplo - duas situações óbvias, porém mascaradas pelas mentalidades ideológicas hipócritas: a) Nada neste Planeta está em equilíbrio (LOVELOCK, 2006, p. 21); b) Nada neste Planeta é infinito a ponto de ser explorado sempre pelas atuais gerações como se fossem as últimas da Terra.

A partir dessas duas premissas, o emprego da Função Ecológica do Estado e do Direito na Pós-Modernidade evidencia quais situações são insustentáveis e se manifestam como discursos falaciosos, sejam os de ordem econômica, do desenvolvimento e progresso a qualquer custo, ou, ainda, aqueles travestidos de adjetivos, como é o caso do uso da palavra "verde" e, ainda, "sustentável".

Sob igual argumento apresentado por Pasold (2013, p. 57) - quando desenvolveu, de modo acertado, a Função Social do Estado contemporâneo -, a Função Ecológica do Estado na Pós-Modernidade é compreendida sob seus aspectos abstrato e concreto. O primeiro refere-se

\footnotetext{
24 “'.... Tudo aponta para a conformação de um novo espaço, que o ‘velho' Estado e o seu Direito tentam contornar, embora não possam mais esconder os sintomas de esgotamento. É preciso reinventar, repensar, as estruturas e estratégias; para tanto, o Constitucionalismo, que ao longo dos séculos tem sido o suporte teórico legitimador e justificador dessas instituições, também precisa ser reformulado”. (GERVASONI, 2017, p. 171).
} 
à sua condição doutrinária, na qual se tem realizado trabalho primoroso na sua perspectiva critica $^{25}$ quanto ao desejo interminável de crescimento econômico ilimitado qualificado como progresso, bem como aos efeitos da insustentabilidade no tempo, resultando, em 1972, a realização da Conferencia de Estocolmo.

O segundo aspecto sinaliza a quantidade de atores transnacionais que viabilizam novas atitudes que contribuem para o aperfeiçoamento e proteção da dignidade da vida - natural e humana - nos territórios do mundo. As redes de cooperação que são tecidas sinalizam a elaboração de mecanismos - legais e burocráticos - para tornar real no espaço nacional os objetivos postos pela Função Ecológica do Estado na Pós-Modernidade. Por esse motivo, apresenta-se, de forma didática e inicial, uma proposta conceitual d que seria a Função Ecológica do Estado na Pós-Modernidade:

a) Quanto ao seu objeto: refere-se à Sustentabilidade;

b) Quanto à sua natureza legal: b.1) nacional: constitucional; b.2) internacional, supranacional e transnacional: pactos, tratados, acordos, especialmente os multilaterais;

c) Quanto aos seus objetivos: c.1) evidenciar as atitudes insustentáveis, desde o âmbito local ao global, a fim de preservar a Sustentabilidade como Bem Comum Global; c.2) preservar toda a cadeia da vida como forma de manter o equilíbrio (não-linear) dos ecossistemas que habitam a Terra; c.3) determinar ao âmbito nacional, pela via constitucional, a concretização de diretrizes em prol do significado ecológico da Sustentabilidade e reforçar o seu caráter de Bem Comum; c.4) identificar os limites do poder soberano, principalmente jurisdicionais, quanto à resolução de conflitos referentes à Sustentabilidade; c.5) tecer caminhos para que

\footnotetext{
25 “[...] Pode-se ter a impressão, num exame apresado deste trabalho, de que a sua utilidade [da Crítica] seja apenas negativa, a saber, de não nos arriscarmos jamais, com a razão especulativa, para além dos limites da experiência; e tal é, de fato, a sua primeira utilidade. Esta logo se torna positiva, porém, quando se percebe que os princípios com que a razão especulativa se arrisca para além de seus limites têm por resultado inevitável não de fato a ampliação, mas, sim, se os observa mais de perto, a contração do uso de nossa razão, já que eles ameaçam alargar indefinidamente os limites da sensibilidade, aos quais eles próprios pertencem, e assim anular o uso puro (prático) da razão. Assim, uma Crítica que limita aquele primeiro uso é realmente negativa, mas, na medida em que suprime ao mesmo tempo um obstáculo que limita o segundo uso, ou mesmo que ameaça destruí-lo, ela tem uma utilidade positiva e muito importante, reconhecível tão logo se esteja convencido de que há um uso prático absolutamente necessário da razão pura (o moral), no qual ela se estende inevitavelmente além dos limites da sensibilidade sem necessitar de qualquer assistência da especulativa, mas assegurada contra o efeito contrário desta para não cair em contradição consigo mesma". (KANT, 2012, par. B XXIV/B XXV. Grifos originais da obra estudada).
} 
haja uma soberania mitigada ou compartilhada entre as diferentes experiências constitucionais, de poder e cultura sobre a Sustentabilidade;

d) Quanto à sua finalidade: d.1) geral: rememorar ao ser humano as causas antropogênicas de destruição quanto aos lugares que habita e as consequências dessa atitude, como é o caso do Antropoceno ${ }^{26}$; d.2) ética: reconhecer como a pluralidade de vidas, seres e territórios não podem ser ignorados, tampouco eliminados, para que hajam atitudes contrárias às situações de "desenvolvimento", de "melhorias", às custas da miséria alheia, seja humana e/ou não-humana;

e) Quanto aos sujeitos: Humanos e Natureza, a qual não se confunde, como se percebe no Direito Ambiental, com o Meio Ambiente (local das relações entre diferentes seres, podendo ser artificial ou natural).

A partir dessas condições, é possível esboçar um primeiro conceito operacional para a categoria denominada Função Ecológica do Estado na Pós-Modernidade: "Atitude empreendida por diferentes atores mundiais que, a partir de sua natureza legal, fomenta critérios de governo e governança a fim de proteger os seus sujeitos e atender às suas finalidades como forma de desenvolver estratégias relacionadas ao Bem Comum e Dignidade, identificados no seu objeto e executados pelos seus objetivos".

Ao se entender a Função Ecológica do Estado, sabe-se da necessidade de se enfrentar a complexidade de interesses num multilevel network de atores para se constituir, nesse caso, a garantia do Direito à Cidade Sustentável. Numa observação mais detalhada e microscópica, sabe-se que as chamadas Cidades Inteligentes e Sustentáveis se reinventam a todo momento. A Função Ecológica do Estado, na verdade, é a aplicação daquilo que se manifesta como Ecologia da Cidade $^{27}$.

Nessa linha de pensamento, a racionalidade da Função Ecológica do Estado na PósModernidade, cujo alicerce é a Sustentabilidade, não pertence tão somente à dimensão da lógica, da metafísica e, tampouco, de uma perspectiva racional instrumental. Não! Não seria o

\footnotetext{
26 "Poluímos o ar que respiramos, degradamos o solo que nos alimenta e contaminamos a água que bebemos. O ser humano parece não perceber que depende de uma base ecológica para a sustentação de sua vida e de seus descendentes". (DIAS, 2016, p. 10).

27 “A reinvenção das metrópoles contemporâneas, no século 21, passa pelos novos indicadores que mostram oportunidades em termos de cidades mais sustentáveis e mais inteligentes do que as que cresceram e se expandiram sem limites no século 20. [...] A ecologia da cidade e não a ecologia na cidade, ou a natureza como um sistema separado na cidade. Um eco-urbanismo ou ecologia urbana. Tratam-se de questões sérias e prementes, independente de rótulos". (LEITE, 2012, p. 8)
} 
caso de se desprezar, também, o termo "Racionalidade Ambiental" cunhada por Enrique Leff, por exemplo, mas a situação requer, ainda, a presença de uma Razão Sensível como mediadora e constituidora de um Saber e Racionalidade da Sustentabilidade.

Somente a partir dessas luzes que surgem pelo ardor, angustias e beleza da vida de todos os dias que o significado constitucional da Função Ecológica do Estado na PósModernidade deixa de ser as promessas não cumpridas da Modernidade, ou, ainda, do tempo presente, mas se torna legitimadora de um Direito à Cidade Sustentável na medida em que constitui a tessitura jurídica entre o local e o global por meio dos diferentes atores nacionais e transnacionais.

\section{CONCLLUSÃO}

A crise ambiental mundial teve êxito em demonstrar não apenas a fragilidade dos processos, estruturas, funções e ciclos do desenvolvimento e manutenção da cadeia vital, mas, para nossa vergonha, a incapacidade humana de compreender os fatores que põem em risco a dimensão relacional de nossa interdependência com a Natureza.

Por esse motivo, a Sustentabilidade não pode ser entendida como simples valor moral. Se essa fosse a intenção, o seu uso indevido, como já ocorre, seria pior. Ao invés de todos se constrangerem por catalogarem os seres e seus ambientes como mercadorias, tudo e todos estariam na vitrine desse grande mercado chamado Terra.

Numa avaliação positiva ou negativa, a Sustentabilidade ainda é o imperativo ético de nosso tempo. Ressalte-se que ao se enfatizar o significado ético, deve-se entender a Sustentabilidade como vetor de avaliação das condutas humanas, as quais se movimentam, inicialmente, entre as dimensões ambiental, econômica e social (triple bottom line). Na medida que a exigência de efetividade da Sustentabilidade demanda cooperação e governança para além dos limites determinados pela força soberana do Estado-nação, deve-se criar instrumentos, especialmente jurídicos, para que a sincronia ente interesses locais e globais ocorra.

Quando a nossa Constituição Federal de 1988 especificou a necessidade de desenvolvimento de politicas urbanas - sintetizadas pela Lei n. 10257/2001, chamada de Estatuto da Cidade - incorporou-se no ordenamento jurídico a necessidade de exigência ao Direito às Cidades Sustentáveis como fenômeno de reinvenção do espaço urbano contra os efeitos da crise ambiental mundial. 
Para fins de atendimento às demandas da Sustentabilidade, a legislação ampliou a Função Social do Estado para que houvesse o cumprimento, agora, da Função Socioambiental do Estado. No entanto, e como se demonstrou, os interesses entre o social e ambiental não são convergentes, o que prejudica o cumprimento da Função Socioambiental como política de desenvolvimento urbano.

Ao se pensar que o espaço urbano se reinventa para abrigar pessoas, seres e ambientes, o Direito às Cidades Sustentáveis somente tem sentido, dentro da lógica da Sustentabilidade, a partir de uma Função Ecológica do Estado. Por esse motivo, a hipótese de pesquisa enunciada nas "Introdução" deste texto foi confirmada, pois para que haja o fiel desempenho da Sustentabilidade em território nacional, junto aos atores transnacionais, a fim de se efetivar o Direito às Cidades Sustentáveis, a Função Socioambiental é incompatível com objetivos de uma Ecologia da Cidade. Nesse caso, a Função Ecológica do Estado se torna a alternativa ao desenvolvimento urbano mais acertada sob o ângulo de um mundo cada vez mais interdependente.

\section{REFERÊNCIAS}

ARAÚJO, Giselle Marques de. Função ambiental da propriedade: uma proposta conceitual. Veredas do Direito: Direito Ambiental e Desenvolvimento Sustentável, Belo Horizonte, v. 14, n. 28, p. 251-276, jun. 2017. Disponível em: <http://www.domhelder.edu.br/revista/index.php/veredas/article/view/985/546>. Acesso em: 02 Jul. 2018.

BECK, Ulrich. Sociedade de risco: rumo a uma outra modernidade. Tradução de Sebastião Nascimento. São Paulo: Editora 34, 2010.

BERTALANFFY, Ludwig Von. Teoria geral dos sistemas: fundamentos, desenvolvimento e aplicações. Tradução de Francisco M. Guimarães. 3. ed. Petrópolis, (RJ): Vozes, 2008.

BUCK, Susan J. The global commons: an introduction. Washington: Island Press, 1998.

CRUZ, Paulo Márcio. Da soberania à transnacionalidade: democracia, direito e Estado no século XXI. Itajaí, (SC): Editora da UNIVALI, 2011.

DIAS, Genebaldo Freire. Antropoceno: iniciação à temática ambiental. 2. ed. rev. e atual. São Paulo: Gaia, 2016.

ELKINGTON, John. Cannibals with forks: the triple bottom line of the 21st century business. Oxford: Capstone, 1997.

GERVASONI, Tássia A. Estado e Direito em trânsito na Pós-Modernidade. Florianópolis: Empório do Direito, 2017.

HAYWARD, Tim. Constitucional enviromental rights. New York: Oxford University Press, 2005. 
HOBBES, Thomas. Leviatan: o la materia, forma y poder de una republica eclesiastica y civil. Traducción de Manuel Sánchez Sarto. 2. ed. Buenos Aires: Fondo de Cultura Economica, 2007.

HOBSBAWN, Eric. Era dos extremos: o breve século XX - 1914-1991. Tradução de Marcus Santarrita. 2. ed. 37. reimp. São Paulo: Companhia das Letras, 1995.

KANT, Immanuel. Crítica da razão pura. Tradução de Fernando Costa Mattos. Bragança Paulista, (SP); Petrópolis, (RJ): Editora Universitária São Francisco/Vozes, 2012.

LEFF, Enrique. Saber ambiental: sustentabilidade, racionalidade, complexidade, poder. Tradução de Lúcia Mathilde Endlic Orth. 11. ed. Petrópolis, (RJ): Vozes, 2015.

LEITE, Carlos. Cidades sustentáveis, cidades inteligentes: desenvolvimento sustentável num planeta urbano. Porto Alegre: Bookman, 2012.

LOCKE, John. Segundo tratado do governo civil e outros escritos: ensaio sobre a origem, os limites e os fins verdadeiros do governo civil. Tradução de Magda Lopes e Marisa Lobo da Costa. 4. ed. Bragança Paulista, (SP)/Petrópolis, (RJ): Editora Universitária São Francisco/Vozes, 2006.

LOVELOCK, James. Gaia: cura para um planeta doente. Tradução de Aleph Teruya Eichemberg e Newton Roberval Eichemberg. São Paulo: Cultrix, 2006.

MANNHEIM, Karl. Ideologia e utopia. Tradução de Sérgio Magalhães Santeiro. 4. ed. Rio de Janeiro: Zahar, 1982.

MATIAS, Eduardo Felipe P. A humanidade contra as cordas: a luta da sociedade global pela sustentabilidade. São Paulo: Paz \&Terra, 2014.

MATTEI, Ugo. Bienes comunes: un manifiesto. Traducción de Gerardo Pisarello. Madrid: Trotta, 2013.

MELO, Osvaldo Ferreira de. Dicionário de Política Jurídica. Florianópolis: Editora da $\mathrm{OAB} / \mathrm{SC}, 2000$.

MILLER, G. Tyler; SPOOLMAN, E. Scott. Living in the environment. 19. e. Boston: Cengage Leraning, 2018.

MÜLLER, Friedrich. Quem é o Povo? A questão fundamental da democracia. Tradução de Peter Naumann. 4. ed. rev. e atual. São Paulo: Revista dos Tribunais, 2009.

PASOLD, Cesar Luiz. A função social do Estado contemporâneo. [recurso eletrônico]. 4. ed. rev. e atual. Itajaí, (SC): Editora da Universidade do Vale do Itajaí - UNIVALI, 2013.

PASOLD, Cesar Luiz. Metodologia da pesquisa jurídica: teoria e prática. 14. ed. rev. atual. e ampl. Florianópolis: Empório Modara, 2018.

SAAVEDRA, Fernando Estenssoro. La perspectiva histórica para comprender el fracaso de la cumbre de cambio climático en Copenhague. Revista Justiça do Direito, Passo Fundo (RS), v. 23, n. 1, 2009, p. 2. Disponível em: «http://seer.upf.br/index.php/rjd/article/download/2158/1392». Acesso em: 03 de mar. 2018.

SAAVEDRA, Fernando Jaime Estenssoro. Medio ambiente e ideología: la discusión pública en Chile, 1992-2002. Santiago: Ariadna/Universidad de Santiago de Chile - USACH, 2009.

STAFFEN, Márcio Ricardo. Interfaces do direito global. 2. ed. Rio de Janeiro: Lúmen Juris, 2018. 
VELD, Roeland Jaap 't. Transgovernance: the quest for governance of sustainable development. In: MEULEMAN, Louis. Transgovernance: advancing sustainability governance. Boston: Springer, 2011.

ZARKA, Yves Charles. O destino comum da humanidade e da Terra. Tradução de Anderson Vichikenski Teixeira. São Leopoldo, (RS): UNISINOS, 2014. 